\title{
El extremo occidental de la Baetica y la vía XXIII Ab ostium fluminis Anae-Emerita del Itinerario de Antonino
}

\section{The western end of Baetica and the road XXIII Ab ostium fluminis Anae-Emerita in the Antonine Itinerary}

\author{
Sergio España-Chamorro \\ Institut Ausonius. UMR 5607. Université Bordeaux Montaigne-CNRS - LabexLaScArBx \\ Maison de l'archéologie \\ 8, Esplanade des Antilles, F-33607 Pessac \\ sergio.espana-chamorro@u-bordeaux-montaigne.fr
}

El extremo occidental de la Baetica ha sido algo conflictivo en cuanto a su adscripción conventual. Igualmente, la interpretación del trazado de la vía XXIII siempre ha sido cambiante y polémica. Los restos arqueológicos asociados a su trayecto pueden ser cuestionados a raíz de nueva documentación de la zona. Todo ello da pie a reformular y reinterpretar las áreas que atraviesa y proponer un nuevo entendimiento geográfico del litoral onubense en época romana.

\section{PALABRAS CLAVE}

VÍAS ROMANAS, BAETICA, POLÍTICA VIARIA ROMANA, ITINERARIO DE ANTONINO, PAISAJE, GEOGRAFÍA ANTIGUA

The adscription into a conventus iuridicus of the western end of the province of Baetica has always been problematic. Likewise, the interpretation of the road XXIII of the Antonine Itinerary has been polemical. The archaeological rests associated to this road can be discarded due to new documents. All of this allows me to reformulate the areas of this road and to propose a new geographical comprehension of the Huelva littoral in the Roman age.

\section{KEYWORDS}

ROMAN ROADS, BAETICA, ROMAN ROAD POLICY, ANTONINE ITINERARY, LANDSCAPE, ANCIENT GEOGRAPHY 


\section{Introducción}

El entendimiento de los límites de los, ya de por sí, complejos sistemas provinciales (Kolb y Zingg, 2016) determina una mejor adecuación de las ciudades y sus territorios, así como su imbricación en la administración romana. Esto permite darnos una imagen ampliada del funcionamiento del Imperio a través del estudio de casos concretos. Las investigaciones actuales están volviendo a interesarse por una mejor definición territorial de dichas unidades administrativas. En concreto, el estudio de los límites de la Baetica está reavivando debates que se creían zanjados y reexaminar cuestiones polémicas a raíz de nuevos datos arqueológicos, epigráficos y enfoques distintos (algunas publicaciones recientes al respecto: Marcos, 2011; Schmidt, 2013; Alves Díaz y Ramírez Sádaba, 2016).

El caso del extremo occidental de la Baetica es uno de esos puntos en los que la investigación ha ido virando de una interpretación a otra. Para entender la problemática que circunda esta zona, es necesario acudir irremediablemente a los textos principales para la interpretación de la costa onubense y la margen final del río Ana (fig. 1). En la descripción pliniana de la Baetica, el naturalista comienza del siguiente modo:

Entre los lugares dignos de mencionar, o fáciles de enunciar en lengua latina, partiendo del río [Ana] y en la costa del Océano, se encuentran la población de Onoba, apellidada Aestuaria, en la confluencia del Luxia y del Urio; los montes Harenos, el río Baetis, la costa Curense, con el recodo de su bahía enfrente de la cual esta Gades — de la que se hablara entre las islas—, el cabo de Juno, el puerto de Besipo, la población de Belo, Melaria, el estrecho del Atlántico, Carteia, llamada Tartesos por los griegos, y el monte Calpe (Plin. NH. III, 5.8, trad. Fontán et al., BCG).

Este pasaje muestra el inicio de la descripción que el naturalista da de la Baetica. La complejidad que encarna esta descripción ha hecho que se creen dos corrientes interpretativas: los que consideran toda la costa como espacio administrativo del conventus Gaditanus y los que consideramos que el pasaje citado sigue un periplo de carácter geográfico y no administrativo, y que la costa se dividía entre el conventus Hispalensis y el conventus Gaditanus. No obstante, la consideración de la primera parte de la costa como hispalense hace que la primera ciudad, Onoba Aestuaria, sea la única ciudad costera de este conventus citada por Plinio. Esta parca ausencia de datos se puede combinar con un análisis más detallado de la vía XXIII del Itinerario de Antonino para entender mejor la estructura conventual.

Esta vía no tiene un trazado que haya sido aceptado de manera definitiva. Existen dos corrientes a considerar: la opción de la vía costera que propusiera ya E. Saavedra (defendida por Blanco, 1962; Luzón, 1975; Roldán, 1975, o Sillières, 1990) y la opción de vía interior iniciada por R. Caro (defendida por Ceán Bermúdez, 1831; Thouvenot, 1973; Tovar, 1972; Bendala Galán, 1986-1987; Tabula Imperii Romani; Ruiz Acevedo, 1998, o Vidal Teruel, 2000). Dentro de estas dos corrientes, han existido, igualmente, numerosas propuestas para su interpretación y la reducción de sus mansiones.

El texto de dicha vía (431.6-432.8, versión de Parthey y Pinder, 1848) indica lo siguiente: 
- Item ab Ostio Fluminis Anae Emeritam usque mpm CCCXIII (sic)

- Praesidio XXIIII

- Ad Rubras XXVIII

- Onoba XXVIII

- Ilipa $X X X$

- Tucci XXII

- Italica XVIII

- Monte Mariorum XLVI

- Curiga XLVIIII

- Contributa XXIIII

- Perceiana $X X$

- Emerita XXIIII

El tramo que ha creado la mayor polémica es aquel entre la cabecera del río Ana y la ciudad de Onoba, que además coincide con la parte que varía en la incorporación a un conventus o a otro. Las ulteriores mansiones no serán objeto de debate por no centrarse en el problema principal y estar mayoritariamente bien ubicadas.

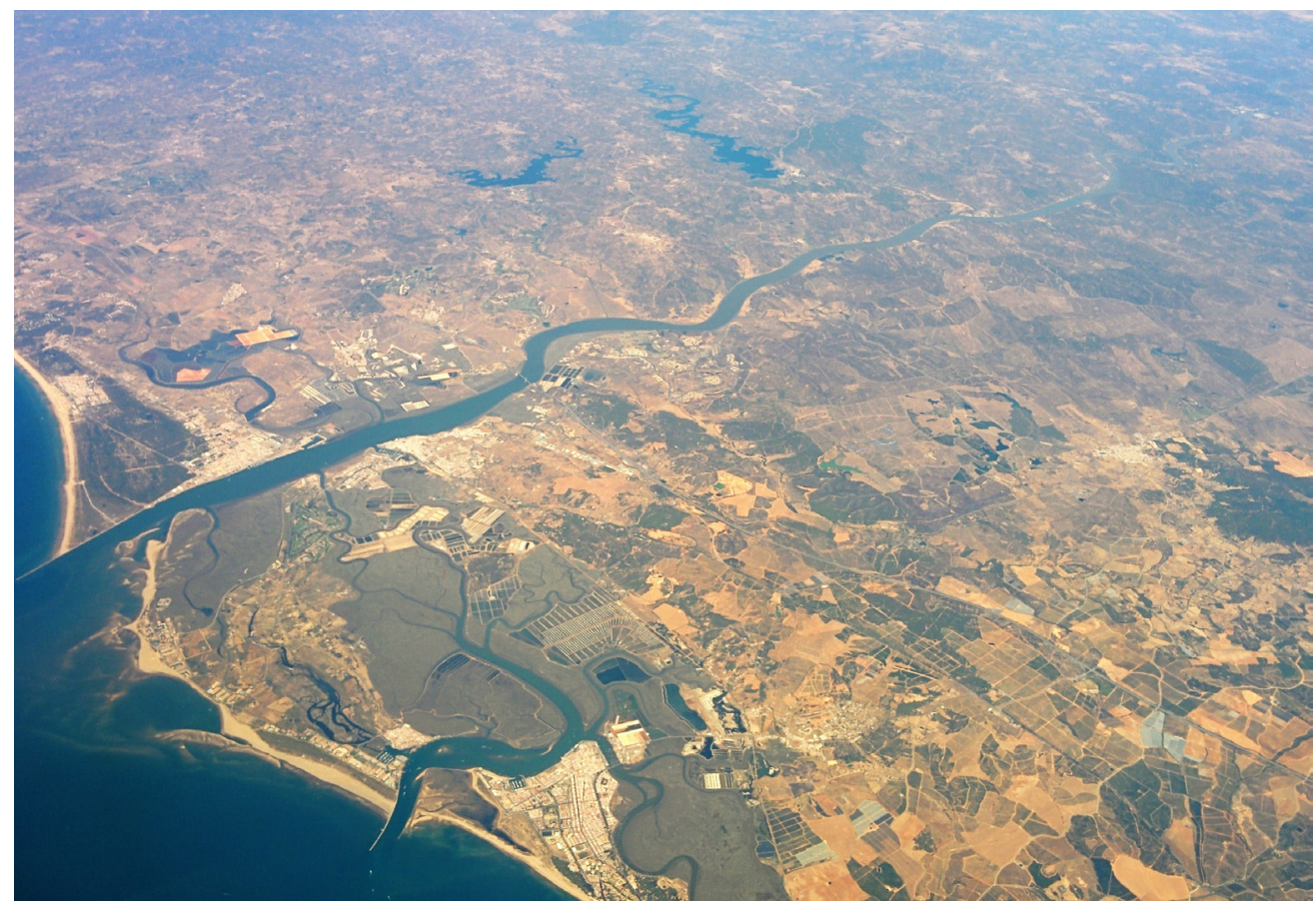

Figura 1. Foto desde satélite de la desembocadura del río Ana (Guadiana) (cortesía de Rodelar, Wikimedia Commons, licencia CC-BY-SA 4.0). 


\section{La historiografía de la vía y la cuestionada evidencia arqueológica}

Las primeras propuestas interpretativas son ya centenarias. Centrándome solo en el debate moderno, hay que acudir a un estudio de J.M. Luzón (1975: 273-274), quien recuperó la idea del trazado costero, al que M. Bendala (1986-1987: 129-139) presentó varias objeciones como un trazado demasiado corto para el número de millas, tramos de difícil acceso como las marismas de los ríos Piedras y Odiel o la falta de yacimientos de importancia en esta zona. P. Sillières (1990: 328-338), el gran conocedor del viario del sur hispano, retomó la idea del trazado costero reajustando las mansiones que ofrecía J. M. Luzón y proponiendo un recorrido diferente al rodear el río Piedras, con lo que cumplía las millas. Las últimas propuestas, entre las que destaca la monografía de J. M. Ruiz Acevedo (1998: 39-56), vuelven de nuevo a retomar la tesis de M. Bendala (1986-1987). J. M. Ruiz Acevedo considera la validez de ambos trazados y reconoce que, con las modificaciones de P. Sillières (1990), su recorrido tendría sentido y salvaría todas las objeciones enunciadas por M. Bendala. Sin embargo, se decanta por la vía interior, a pesar de decir que serían varios trazados de una misma vía, ya que no tendría sentido dar una vuelta tan larga para ir del Odiel al Ana. Este autor combinó su estudio con interesantes prospecciones destinadas a encontrar evidencias físicas de la vía. Estas dieron sus frutos y, proponiendo la mansio (Ad) Praesidium en Sanlúcar del Guadiana, (al igual que ya argumenté que la mansio Fines debió ser, en origen, Ad Fines, España-Chamorro 2018b: 190-191, creo que en este caso sería igual, debido, entre otras cosas, a que no habría habido una mansio en un destacamento militar, pero sí en sus proximidades; la pérdida de la preposición en las fuentes itinerarias tardías es visible en la via Augusta, que permite comparar la toponimia legada en los Vasos de Vicarello y el Itinerario de Antonino; para las apreciaciones metodológicas remito a mi artículo ya mencionado), J. M. Ruiz Acevedo exploró la zona y descubrió un sistema de infraestructuras (fig. 2) que llevaba a desembocar en el Ana, cuyas características físicas le permiten hacer la siguiente aseveración:

Todos ellos tienen unas características constructivas idénticas: a uno y otro lado del arroyo se elevaron unos muros que hacían la función de estribos, de anchura similar a la de la calzada, unos cuatro metros (Lámina 5). En las caras internas de ambos estribos, que quedan enfrentadas, se abren unos mechinales donde iban alojadas unas gruesas vigas de madera. Éstas soportaban el peso de la pasarela de madera que permitía franquear el arroyo. Casi todo el recorrido de la calzada discurre elevado mediante un arrecife, a veces separado de la pared de la ladera en la que se asienta por una amplia zanja que hace las veces de cuneta (Ruiz Acevedo, 1998: 47).

Esto también fue indicado por N. de la O Vidal Teruel (2000: 61 y ss.) en su tesis doctoral, quien lo define como 'tramo monumental', a lo que añadía que existía un tramo inacabado que se remozó en algunas de sus partes en el siglo xix. Ella misma indica otros tramos como el intento de reutilizar una vía romana para construir una conexión de 

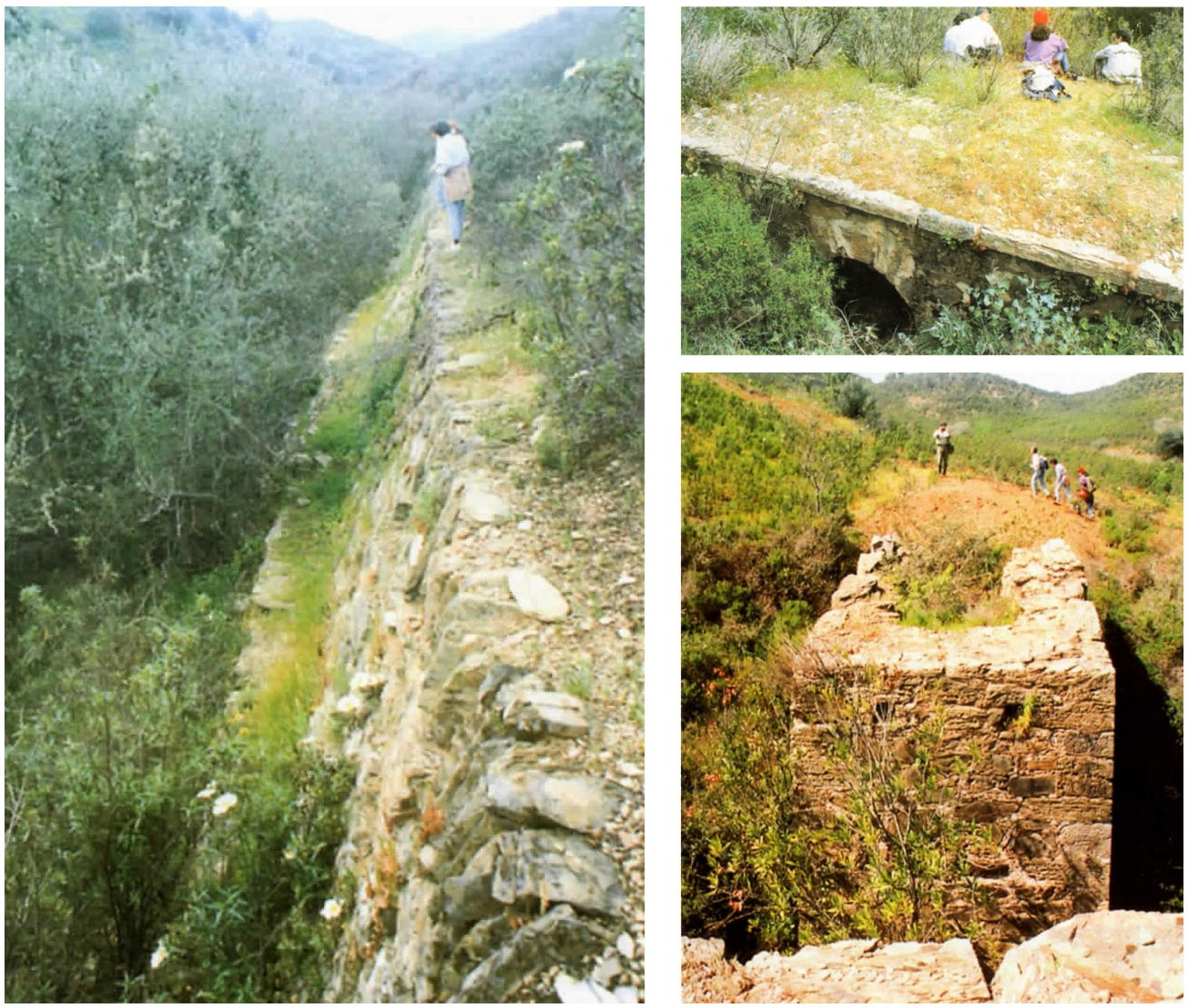

Figura 2. Infraestructuras de la plataforma y obras de infraestructura del ferrocarril (Ruiz Acevedo 1998: 142-143, láms. 3 a 5).

ferrocarril en Riotinto por D. Joaquín Ezquerra (autorizado en 1853, aunque no llegó nunca a realizarse), pero matizó que este proyecto no habría pasado en la zona de Cabezo de los Estandartes (lugar donde se indica la estructura monumental), ya que no existen evidencias de explotación minera que lo hiciesen necesario, puesto que la vía XXIII se abandonaría tras la Edad Media.

No obstante, los nuevos estudios de I. Carrasco Martiáñez sobre minería onubense durante el siglo XIx han sacado a la luz los planes de explotación de las minas de El Lagunazo. Tras dos intentos fallidos (Lagunazo Sulphur and Cooper en 1860 y el empresario barcelonés Dr. Andrés Baradat i Vera), el último y más interesante proyecto que interesa con respecto a la vía XXIII es la empresa que acometió la sociedad Miguel Yglesias e Hijos, constituida en Londres con capital privado. Esta empresa no solo quería centrarse en El Lagunazo, sino, además, en las minas de su entorno, las cuales se unirían con el 


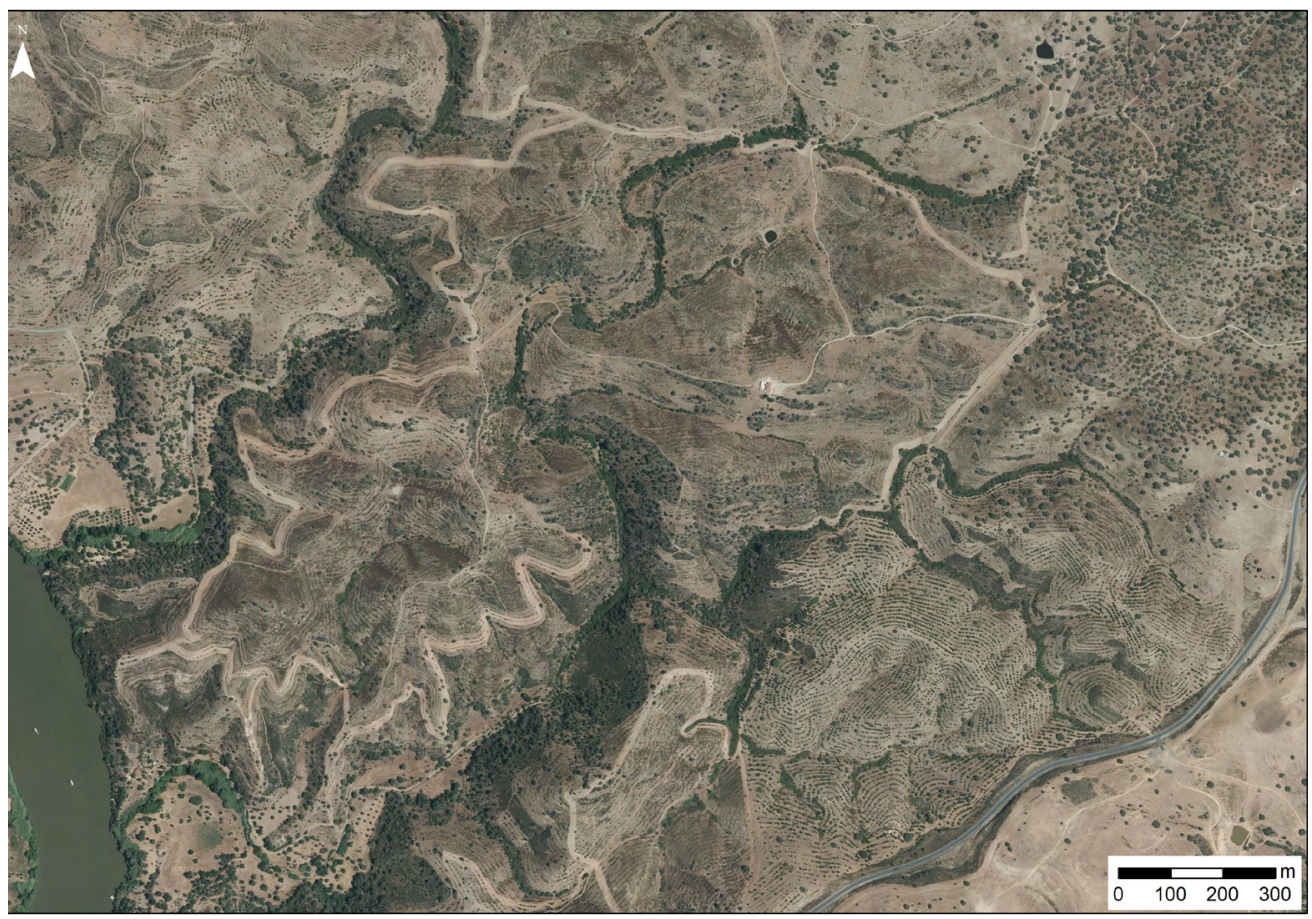

Figura 3. Ubicación de parte del trazado de las infraestructuras del siglo XIX. Imagen elaborada a partir de las ortofotos de PNOA-2016 al norte de Sanlúcar del Guadiana (la carretera que se ve es HU-4402, lat. 37²9' 39.16”, Ion. 7²6' 39.28”) (cortesía de M. Alba Luzón).

Guadiana a través de una línea férrea de $35 \mathrm{~km}$, como en el proyecto anterior. Eso permitiría comunicar la mina con el puerto fluvial de Sanlúcar del Guadiana. Las obras se iniciaron simultáneamente tanto en la mina como en el río, las cuales, no sin falta de problemas, siguieron ejecutándose hasta el 31 de julio de 1876, cuando la sociedad decidió renunciar al proyecto por falta de capital (vid. Carrasco Martiáñez, 2015: 80-87). Se sucederían algunas propuestas ulteriores, las cuales no llegaron a nada. Los restos monumentales no se corresponden con la preparación de una vía romana, sino con el basamento de la estructura viaria del ferrocarril, que llevaba directamente a Sanlúcar. Como indica N. de la O Vidal (2001: 293 y ss.), no hubo un intento de explotación minera en la zona, sino que hubo ni más ni menos que cuatro o cinco, de los cuales el único que llegó a materializarse, aunque de manera inacabada (fig. 3), fue el de la compañía londinense. Su trayecto se ve perfectamente expuesto en el plano propuesto (fig. 4). Los argumentos de J. M. Ruiz Acebedo declinaban la balanza del trazado de la vía XXIII por esta zona, ya que lo vinculaban a restos de infraestructuras viarias de considerable envergadura. Una vez descartada esta hipótesis, es necesario replantear de nuevo la cuestión. Sin intención de hacer cíclica la historia, veo más plausible pensar en un itinerario costero al estilo del que prospectó y propuso P. Sillières (1990: 330 y ss.). 
MAP OF GUADIANA AND HUELVA MINING DISTRICT, SHEWING PROPOSED RAILWAY.

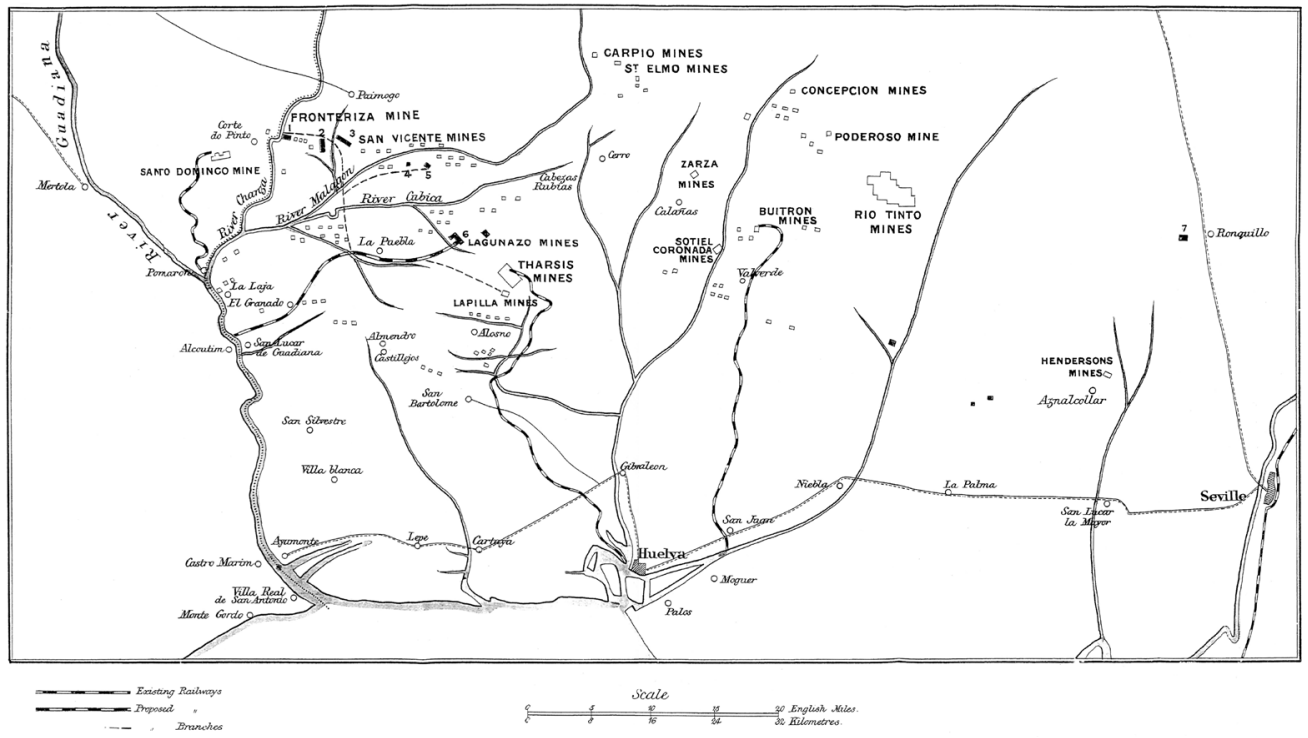

Figura 4. Plano de ferrocarriles del Guadiana que recoge la propuesta de construcción de la vía férrea por la casa Miguel Yglesias e Hijos (documento AGA, 25-02522-00007).

\section{3. ¿Trazado costero o trazado interior?}

¿Por qué decantarse por el trazado costero? Es evidente que las minas de la actual Tharsis fueron explotadas en la Antigüedad de manera intensiva. Luzón (1975: 318-319) indica unos 7 millones de toneladas de escoriales antiguos, solo superadas por los de Urium (Minas de Riotinto), con unos 20 millones (p. 315), pero parece más lógico que este gran núcleo minero fuese conectado antes con la ciudad de Onoba (a unos 50 km), ciudad costera y gran puerto, en vez de un con punto incierto, quizás un embarcadero próximo a Sanlúcar del Guadiana (a unos $40 \mathrm{~km}$ ) que actuase como puerto fluvial; por tanto, dependiente de la estacionalidad de su caudal, del que Estrabón (III, 2, 3) da la noticia de que es navegable, pero con embarcaciones de menor calado que el Baetis. Además, debido al gran volumen minero de Tharsis, se habrían encontrado ya grandes estructuras portuarias para tal fin, y no los restos aislados que han sido documentados (Ruiz Acevedo, 1998: 48: «Precisamente al principio del tramo descrito, donde calzada y arroyo desembocan en el río Guadiana, se forma una pequeña ensenada que pudo servir de zona de atraque y de embarque y en sus aledaños pudieron levantarse los edificios propios de una zona portuaria. Restos constructivos (tégulas, ladrillos) y cerámicos fueron hallados en gran parte del arco de la ensenada, lo que confirma la presencia romana en este lugar.»); por esto el viario del sector minero estaría, siguiendo la practicidad romana en la explotación económica 
de los recursos mineros, orientada preferentemente a un puerto marítimo de importancia que hiciese más fácil su embarque en naves de gran calado - las minas de la comarca de Cástulo estaban orientadas a Almería (¿Portus Magnus?) y las del conventus Carthaginensis, hacia Carthago Nova; la administración romana en general estaba orientada hacia puertos de importancia, tanto fluviales (Astigi, Corduba, Hispalis), como también y, sobre todo, marítimos (Gades, Carthago Nova, Tarraco y, aunque no fuesen administrativamente puntos neurálgicos, Oiasso y Olissipo); para las relaciones entre navegación, administración y disposición geográfica vid. Ozcáriz Gil, 2006: 100-104. Además, habría que pensar seriamente si un camino extraído de un itinerario oficial favorecería una ruta de unos 130-140 km en vez de otra de $70 \mathrm{~km}$ (la suma de esta zona da $118 \mathrm{~km}$ en el Itinerario de Antonino, por lo que o es muy corta por la costa o muy larga, por el interior). Que las millas no casasen y, en este caso, diesen más de la realidad, es de momento un problema sin solución. Ruiz Acevedo (1998) ya indicó dicha anomalía, pero también hay que recordar que la había remarcado antes Sillières (1990: 29) en su estudio sobre todas las vías meridionales. En otros casos, como en la vía XXI (Item de Esuri Pace Iulia), propuse un problema de transmisión en los empalmes (España-Chamorro, $2019 \mathrm{~b}$ e/p), aunque para esta vía no se podría aplicar la misma corrección, por lo que queda de momento sin solución definitiva.

Viendo la polémica cíclica que se da y la circunstancialidad de las pruebas, la solución no parece fácil y, quizás, se deba buscar una justificación de dichas descripción y planificación viaria en las dinámicas sociohistóricas, pero también en el modelo de proyección antiguo (para las diferentes propuestas, vid. fig. 5).

Como punto de partida, es necesario poner esta vía en relación con las otras nombradas en el Itinerario de Antonino. Se puede ver que, a excepción del macizo Cantábrico, de una orogenia abrupta y con un sistema viario que discurre por los valles debido al modelo de asentamiento disperso (un indicio claro es el gran número de miliarios —el único corpus hasta el momento es el de Rodríguez Colmenero et al., 2004- hallados en los numerosos valles de la región, lo que prueba la profusión de vías, así como del anómalo patrón de amojonamiento en comparación con el resto de la Península), la práctica totalidad de las vías que conforman el contorno peninsular están descritas, generando la imagen figurada, lo que no impide que se describa también su interior con la descripción de las vías interiores. En la mentalidad hodológica (vid. Janni, 1984; González Ponce, 1990, y España-Chamorro, 2017), las vías costeras permiten dibujar la imagen mental externa de una entidad tan abstracta como es una península. Eso es lo que se intenta hacer de manera específica con la Baetica, como ya señalara M. L. Cortijo Cerezo (2008: 292-294). En algunos tramos se evita una descripción directa, como la vía VI entre Castulo y Gades, que obviamente no sigue una línea directa, sino que empalma varias vías que permiten hacer un perfil costero de todo el territorio occidental de la provincia hasta Gades. Hay que pensar, además, que el Itinerario de Antonino, aunque sin seguir recorridos coherentes a simple vista, recoge los ejes principales de movilidad. ¿Qué propósito tendría unir Onoba con la desembocadura de un río? Este es el único caso de Hispania donde una vía no se inicia en una ciudad de importancia. M. L. Cortijo Cerezo (2008: 294) indica que esta ruta parte de dicho punto para querer 


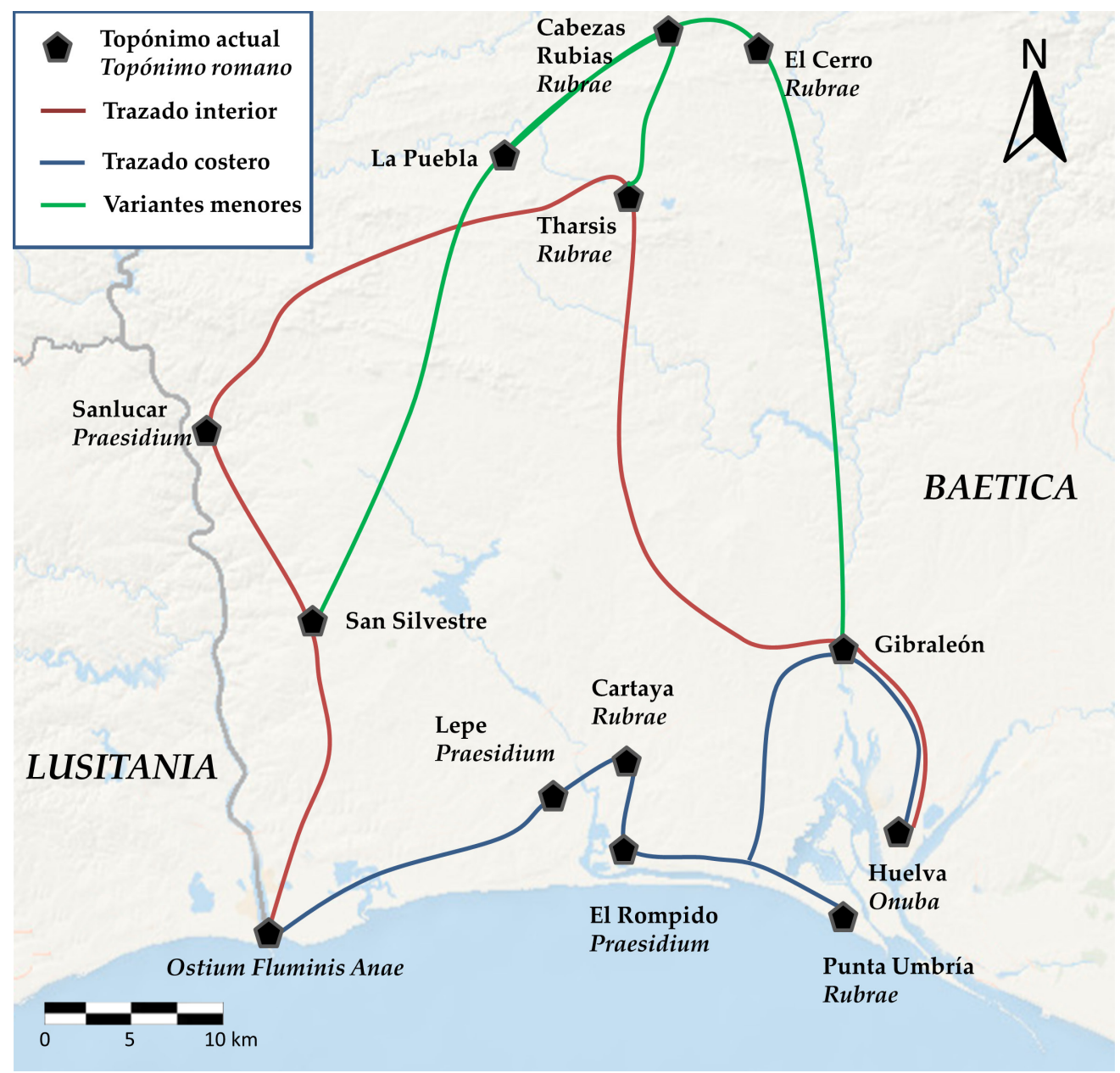

Figura 5. Propuestas de ruta entre Ostium fluminis Anae y Onuba (comparación del trazado marítimo y del trazado interior).

cerrar la línea de agua; es decir, el contorno costero de la Península. De hecho, las vías V y VI cierran la línea costera desde Murgi hasta Hispalis pasando por Gades y orillando el Lacus Ligustinus, mientras que la vía XXIII igualmente contornea dicho lago y recorrería la costa onubense hasta el confín provincial. Si bien esto parece perfectamente lógico y habría una necesidad de narrar la costa (como se puede ver en las descripciones geográficas antiguas con Plinio a la cabeza), hay que echar un vistazo a la costa atlántica lusitana para entenderlo. El Item de Esuri Pace Iulia (la polémica vía XXI que ya he tratado de manera monográfica en otros trabajos, vid. España-Chamorro, 2018b y 2019b e/p) se inicia en una población o mansio llamada Esuri y de ahí a Balsa, citada en las fuentes clásicas (It. Ant. 426, 1; Rav. IV 43 (306, 10); Mela III 7; Plin. IV, 116; IV 118; Marcian. Her. II 13; Ptol. II 5, 2; origo 
Balsensium CIL II, 4989 = CIL II, 5161 = IRCP 80; origo Bals(ensi) CIL II, $4990=$ CIL II, $5162=$ IRPCa 79; incola Balsensis CIL II, $105=I L S 6902=H A E 147=A E$ 1967, $129=I R C P 294=A E$ 2000, 668; Bals(ensium) disp(ensator) CIL II, 5164 = IRCP 74; otra mención, en EE IX, n. ${ }^{\circ}$ 12) y cuya documentación epigráfica demuestra su reducción en Tavira (Roldán, 1975: 220). Esuri (It. Ant. 431, 4 (ab Esuri). 425, 6 (de Esuri). Rav. IV 43 (306, 9); Roldán, 1975: 237), cabecera de dos vías, se relaciona con Castro Marim a raíz del hallazgo de una moneda que, además, permite corregir el topónimo antiguo a Baesuri a través de la leyenda monetal (CNH Baesuri 1 = RPC S-53A). Las relaciones entre toda la costa atlántica lusitana y el valle del Baetis vienen de lejos, como ya propusieran M. Almagro y M. Torres (2009: 113-142), lo que justificaría no solo una intensa red comercial marítima y fluvial, sino también un eje de contacto directo. Habría que ver cómo se salvaría la desembocadura del Ana - pero no es raro suponer una conexión fija desde algún punto bético en las cercanías del actual Ayamonte, ya que se salvan las marismas de Isla Cristina y, como indica P. Sillières (1990: 333), sería el primer monte que sortearía las dificultades del entorno- situada justo en frente de Castro Marim (Portugal), donde no cuesta imaginar algún tipo de muelle que facilitase la conexión mediante barcas o, por qué no, un trasbordador: una simple barca atada en ambos extremos, que permitiera un paso constante e, igualmente, no impidiera la navegación de barcos y barcazas por el Ana. Toda esta argumentación sirve para repensar la vía XXIII como una conexión directa desde el corazón de la provincia Baetica hacia la Lusitania y no de un simple tramo secundario viario que uniese Onoba con la desembocadura de un río donde, en principio, no existe un asentamiento urbano de relevancia. Cuesta mucho creer que una conexión interprovincial por tierra y de tanta importancia para ser referenciada en el viario imperial fuese una vía marginal sin destino claro, lo que inclina la balanza a pensar en el trazado costero.

P. Sillières (1990: 337) propone la ubicación de la segunda mansio de la vía, (Ad) Praesidium, en la llamada casa del Castillo de San Miguel, donde documentó un yacimiento desde época prehistórica que perduraría al Bajo Imperio, aunque nuevos indicios apuntan a una ausencia de poblamiento romano. No obstante, eso no impide que se hubiese establecido un asentamiento en la zona. Él proponía que un asentamiento militar a la entrada del río lo protegería. ¿Hubo un destacamento militar? El topónimo apunta en esa dirección. Al ser la Baetica una provincia de consideración senatorial, la presencia militar sería mínima, aunque no imposible, como se sabe a través de la epigrafía (González Fernández, 1994: 179-188). Cuesta ver las razones por las que se instalaría aquí un destacamento militar. El río Piedras no parece una zona de interés para requerir un destacamento fijo. Si no se piensa en el río, habrá que pensar en la costa, pero, ¿cuándo habría hecho falta tal destacamento? La información principal del Itinerario de Antonino parece venir del siglo III, aunque incorpora algunas adendas del IV. No obstante, las razzias vándalas del siglo v a zonas del Atlántico quedarían descartadas. Pero a finales del siglo ir se produjo un hecho que debió de tener más magnitud de lo que las fuentes cuentan: la invasión de los mauri de zonas de la Baetica —existe una evidencia epigráfica en Itálica (CIL II, 1120)—. Hay algunas fuentes que indican que estas invasiones afectaron genéricamente Hispania, cuando 
la peor parte, si no toda, se la llevó la Baetica. Así lo vemos en un pasaje de SHA, Vit. Ant. XXI, 1, además de la inscripción de Lucio Iulio Vehilio Grato Iuliano (ILS 1327) que se enfrentó a los mauri en Hispania. La confrontación y el asedio directo con Singilia Barba se conocen a través de la epigrafía (CIL II, $2015=I L S$ 1354a = HAE $977=$ AE 1961, 340 $\left.=H E p 1,469=C I L I^{2} / 5,783\right)$, lo que demuestra que las poblaciones penetraron hacia zonas interiores. En un pasaje de los Scriptores Historiae Augustae (Vit. Seu. II, 4) se indica que el que sería el emperador Septimio Severo no pudo desempeñar el cargo de cuestor de la Baetica, ya que sus tierras estaban siendo pobladas y saqueadas por el grupo norteafricano. La invasión ocasionó que se cambiase eventualmente su estatuto a imperial, lo que suponía que el emperador tomaba el mando para actuar y poder enviar legiones, que en este caso fue la Legio VII Gemina, conocida así por hallazgos epigráficos en Italica (ERIt 60 y 70). No obstante, parece ser que la invasión duraría poco tiempo ( 1 o 2 años a lo sumo), pero habría otra nueva incursión en el año 177. Es posible que se acantonasen algunos destacamentos militares en puntos de interés estratégico con el fin de proteger de ulteriores incursiones, además de asegurar la importación metalífera de la zona. Puede ser que (Ad) Praesidium tuviese ese papel en la costa onubense que, aunque quizás efímero, habría permanecido en la toponimia. Esta debía de ser muy diferente, como muestra L. López (1999: 1 1-13). La lengua de arena que hoy en día existe en la desembocadura del río Piedras es el resultado de un proceso de colmatación de su laguna y de la sedimentación con esta transformación (el mismo proceso que en Punta Umbría). En época romana este problema de los arenales no existió y la costa de El Rompido, según indica L. López, era un frente rocoso, por lo que pudiera haber sido un punto de resguardo de embarcaciones, sobre todo de transporte, a la par que de vigilancia (fig. 6).

Los defensores del trazado interior sitúan esta mansio en Sanlúcar del Guadiana, pueblo que está presidido por un castillo moderno que sería el lugar para el destacamento

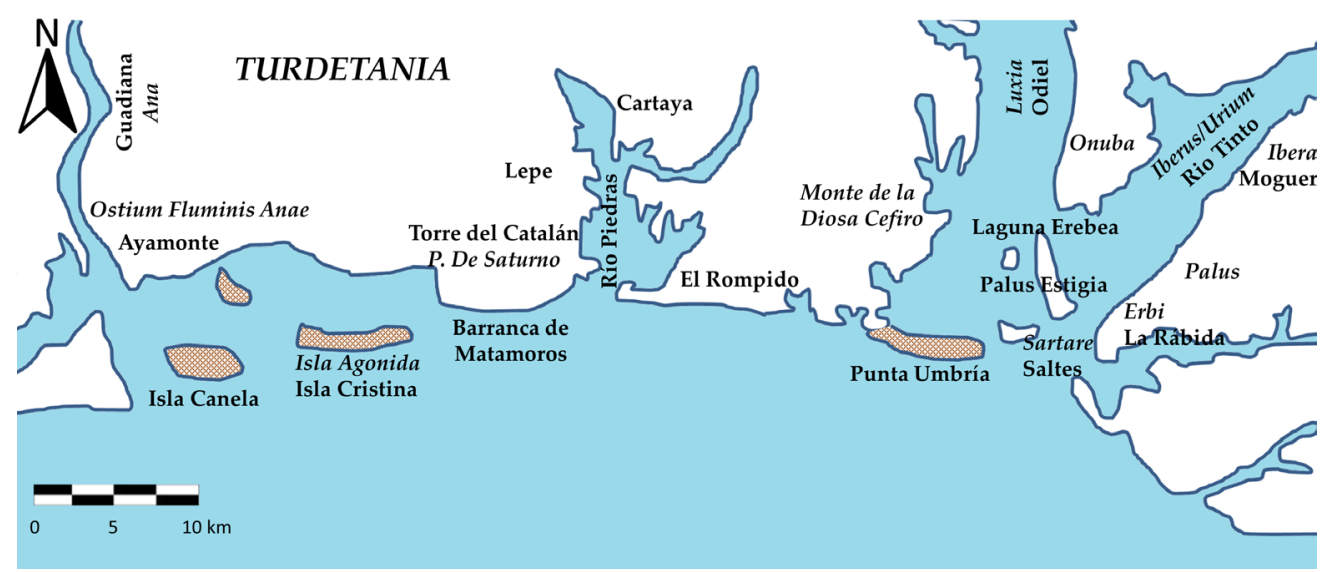

Figura 6. Morfología de la paleocosta onubense en época prerromana-romana (autor, implementando la propuesta de L. López, 1990: 20, fig. 1). 
militar. J. M. Ruiz Acevedo expresa cierta rareza en situar un destacamento interprovincial, ya que en principio no tendría sentido. Él lo explica con una finalidad de vigilancia de los caminos y la zona de embarque (Ruiz Acevedo, 1998: 42-43), pero cuesta pensar que se dedicase un destacamento militar de manera concentrada, cuando en otros puntos peninsulares como el distrito de Castuera, algunas zonas mineras de Lusitania (Maia, 1986; Fabião, 2002) u otros puntos de minería en la Península han revelado redes de pequeños castella dispersos a lo largo de las vías de comunicación que premian una seguridad en el recorrido y no solo en un punto concreto. Del mismo modo, esa red de castella miliaria a intervalos regulares se ha documentado en Huelva, pero no en la zona entre Sanlúcar del Guadiana-Cabezas de Rubia, sino en otros lugares como la Rivera de Casa de Valverde (Castillejo del Zau, Castillejo de la Revuelta del Risco, Alcazarejo y Cerro Salomón), en el área de Paymogo (Rivera de Malagón, Romanera, Vuelta Falta, Sierrecilla, Silos de Monterrubio y São Domingos), en el camino de Riotinto a Tejada la Vieja (Cerro del Drago, Castrejón de Naja y Castrejón de Juan de Aracena) y en las vías a Aracena y Beja (Pérez Macías, 201 1; 2015). J.A. Pérez Macías indica que dichos proyectos comparten cronología augustea, planta cuadrangular y abandono de su uso en época flavia. Todos ellos, además, son comparables en su emplazamiento en zonas de complicada orogenia para el tránsito de personas y mercancías y su objetivo, como elemento protector de los caminos, se evidencia al encontrarse en zonas donde existe necesidad de vigilancia, pero nunca en las minas mismo. Por ello, si la vía XXIII hubiese discurrido por la zona interior, habría contado con esta infraestructura, cosa que de momento no se ha documentado. Otro punto que tampoco parece evidenciar el trazado interior es que la mansio (Ad) Praesidium sigue manteniendo tal nombre en las fuentes itinerarias tardías a pesar de que los castella se abandonan en época flavia, pudiendo darse una fosilización del topónimo o, mejor, por que tal destacamento siguiese en uso.

(Ad) Praesidium estaría ubicada en las inmediaciones del complejo castrense que le daría su nombre, quizás en la misma Cartaya o sus cercanías, donde se han encontrado evidencias de asentamiento rural disperso (Bendala Galán, 1986-87: 130).

Ad Rubras es difícilmente discernible (la opción de los que consideran la propuesta interior es Cabezas Rubias como una fosilización toponímica), ya que no existen indicios que ayuden a reducir esta mansio más que las millas, que no parecen cuadrar. Las suposiciones de P. Sillières llevan a emplazarlas en las inmediaciones de Aljaraque por los restos arqueológicos de la zona. Es difícil saber a qué se refería en origen dicho adjetivo sustantivado, pero, dada la concentración de metales pesados arrastrados por los ríos Luxia y Urion, esta bahía pudo tener un aspecto más rojizo en la Antigüedad y pudiera referirse al color de las tierras (Correa, 2016: 425, cree que puede referirse a árboles mejor que a tierras; ambas opciones son válidas, al ser femenino plural). Existen otras dos mansiones con el mismo apelativo: una en Italia, Ad Rubras, estación junto a Saxa Rubra (Ad Rubras es citada en la Tabula Peutingeriana, que vendría a decir 'estación junto a la ciudad de Saxa Rubra', citada en Liv. II, 49 y en Tac. Hist. III, 79, reducida aquí por Phil, 1921: 307), que se ha puesto en relación con Grottarossa (una cueva excavada en tufo rojizo, en las inme- 
diaciones de la salida norte de Roma por la via Flaminia), y otra en Numidia, conocida por la Tabula Peutingeriana en la vía Theveste-Cirta, a seis millas de Gadiufalla (también en It. Ant. p. 36 y Rav. 156,9; Dessau, 1914: 1166).

La vía continúa por Ilipa (Niebla), (I)tucci (Tejada la Vieja) e Italica, estaciones que en principio no presentan ningún problema de adscripción geográfica. Ilipla, o más bien Ilipula (es la forma que da Ptolomeo; existe una tendencia a la síncopa de vocales átonas en la serie -ipo al igual que Ilpa, Silpa... y Serpa, vid. Villar, 2000: 97, 117, 386.), ciudad homónima a otras ciudades del valle del Baetis, es citada por Ptolomeo (II, 4, 12) y como mansio de esta vía tanto en el Itinerario de Antonino como en el Ravenate y, a pesar de su escaso número de inscripciones, está confirmada solo por un epígrafe que habla sobre un decurión Ilipu[lensis] (CIL IX, 628* = CIL II, $954=$ CILA 1, 73), sin otras menciones de origo de la misma ciudad (a excepción de un foráneo que se describe como Cantibedonensis en la tessera muneris: Celer Erbuti f(ilius) / Limicus / Borea Cantibedoniensi / muneris tessera dedit / anno $M($ arco) Licinio co(n)s(ule) HEp 1, $357=H E p ~ 2,428=H E p ~ 3,228=C I L A ~ 1,72=B J R A$ 23). El único epígrafe de toda la provincia que cita un ord(o) (splen)ididissimus (sic) (CIL II,955; Luzón, 1975: 280, n. ${ }^{\circ}$ 19) fue encontrado en Bollullos Par del Condado, próximo al lagus Ligustinus. Este epígrafe aislado fue encontrado en un lugar en donde se evidencia una necrópolis y restos dispersos de poca importancia, pero la mención de ordo indica una ciudad privilegiada de algún tipo. E. Hübner propuso ubicar aquí Illipula (Ilipla), opción claramente descartada por lo indicado anteriormente. Este epígrafe demuestra una mención aislada, por lo que cabría interpretarlo bien como un homenaje en un fundus privado al estilo de otros casos béticos (Melchor Gil, 2013), bien por que fue trasladado desde otro núcleo, lo que indicaría el privilegio de una de las ciudades de las que está equidistante, Ilpla e Itucci.

(I)tucci, por su parte, no es citada más que por Ptolomeo (como Iptucci) y como mansio de esta vía en el Itinerario de Antonino (Tucci). La reducción geográfica se hace por monedas de la ceca de Itucci que aparecen en el entorno de Tejada la Nueva y próximas a este yacimiento. No hay ninguna prueba epigráfica, salvo la excepción de una inscripción antigua transportada a Sevilla, sobre la que algunos se basan para atestiguar aquí un municipio flavio por el cargo de IIvir de Quinto Cornelio Senex, de la tribus Quirina (CILA 1, 84; Canto de Gregorio, 1979: 333; Morales Rodríguez, 2001: 309-311). No obstante, no existen otros epígrafes que permitan su vinculación, aunque está ampliamente aceptado el topónimo antiguo, a falta de ulteriores evidencias. De Italica sí que no hay duda, por numerosas pruebas arqueológicas, históricas y epigráficas.

Entre Ilipa e Itucci se ha propuesto la ubicación de otra ciudad no citada en el Itinerario de Antonino: Ostur. La inscripción de Iunoni Regina (CIL II, $1267=$ CILA 1, $81=$ Luzón, 1975: 301 ) encontrada en Villalba del Alcor ha dado pie para ubicar en su entorno la ciudad mencionada y, en concreto, en el yacimiento de la Mesa del Castillo: La primera identificación con este yacimiento fue la de González Fernández y Pérez Macías (1986: 259-268) y posteriormente se volvió a relacionar en un estudio monográfico (Robles Esparcia et al., 201 1-2012: 75-94), en donde indican que las prospecciones reali- 
zadas revelaron algunos materiales cerámicos que indicaban un potente nivel turdetano del siglo IV aC y una fase romana con algunas sigilatas itálicas y sudgálicas. En ningún momento se habla de estructuras que puedan corresponder a un oppidum). Esta ciudad no se cita en los textos clásicos y solo está documentada por dos emisiones numismáticas del siglo II-I aC (vid. 'Ostur', 1 y 2. (s.v.) DCyPH, 314). Tampoco existe epígrafe alguno que aluda a tal topónimo (ni de carácter administrativo ni menciones de origo) o restos en este lugar (Morales Rodríguez, 2001: 31 1-313) que hagan pensar en la existencia de dicha ciudad. Tan solo se conoce un fragmento de un posible pedestal con inscripción muy fragmentaria (CIL II, $1258=$ CILA 1, 82), además del ya citado epígrafe de Iunoni Regina, de una fecha posterior a 143, por la prefectura de la flota de Rávena. Si, en verdad, la ciudad de Ostur existió en este solar, cosa de la que no hay pruebas fehacientes, parece que no perduró en época romana, al menos de manera importante y como ciudad independiente. Esta inscripción pudo llegar de Ilipla o Itucci, o más difícilmente de alguna estructura rural (vicus, pagus, fundus) asociada a una de las civitates anteriores, ya que, por la dedicación de estatua y el banquete, es de suponer un ámbito urbano de importancia. De este personaje se conocen otros epígrafes en Hispalis en los que se indica que el ordo coloniae Romulae le dedica una estatua, así como en Ilipa Ilia, por lo que habría que pensar que, igual, la dedicación se hizo en la misma Hispalis, próxima a este lugar. En todo caso, con tan poquísimas pruebas, es difícil afirmar que exista una hipotética Ostur en la provincia en época imperial. Es posible que esta antigua población, presente en la Ulterior republicana (si de verdad se llegase a confirmar la adscripción donde ahora se reduce geográficamente), se trasladase a otro núcleo próximo o, más fácilmente, que quedase relegada a un simple vicus (Robles Esparcia et al., 2011-2012: 86 y ss., llegan a proponer una municipalización flavia). Del cercano pueblo de Manzanilla existe otra dedicación (AEp. 1979, 348), esta vez a Diana Augusta, también del siglo II, en la que Fabia Prisca acepta ex decreto ordinis loco, sin que se sepa a cuál de las ciudades circundantes pudo hacer referencia. Una posibilidad es Olontigi.

El resto de la vía (vid. la propuesta en fig. 7), como comenté en la introducción, no suscita problemas relativos de consideración, conociendo la ubicación clara de la próxima mansio, Italica, y el destino de la vía, Emerita. Como apunte final sobre las mansiones que se disponen a lo largo de esta vía, tan solo haré una última apreciación. En las noticias que proporcionaba J. M. Luzón Nogué (1975: 275 y 308: «Otra fuente puede ser la localización de columnas miliarias, pero desgraciadamente la única que menciona Hübner en el C.I.L. no es tal cosa. Recientemente hemos tenido noticias del hallazgo de una columna con inscripción en las inmediaciones de Candón, pero ha sido trasladada a Valverde del Camino para la construcción de una ermita y no nos ha sido posible tomar fotografías ni datos directamente»), dicho autor hablaba de la aparición de una 'columna con inscripción' que fue hallada en Candón, pero en ningún momento indicó que fuera un miliario; sin embargo, P. Sillières (1990: 331) la definió en su estudio como noticia de un 'borne milliaire' al igual que N. de la O Vidal (2001: 59). Con todo, J. M. Luzón parece expresar sospechas sobre su uso como miliario y nunca lo definió como tal, aclarando que no la 


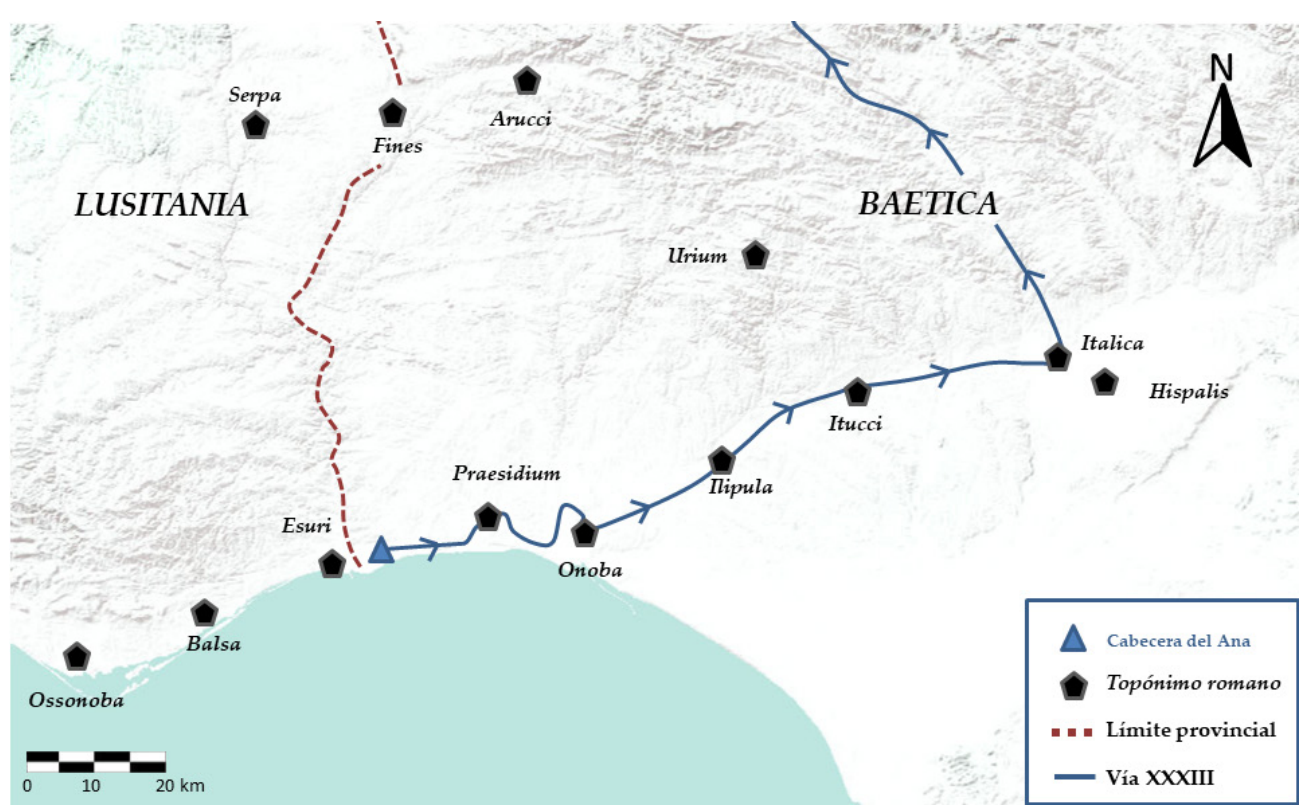

Figura 7. Trazado de la vía XXIII (según propuesta del autor) y ubicación de los topónimos citados (autor).

vio y tampoco dio texto. Dadas las pautas de amojonamiento bético (España-Chamorro $2018 \mathrm{a}$ y, especialmente, $2019 \mathrm{~b}$ e/p), es bastante improbable que pudiese haber cualquier tipo de inscripción miliaria en toda esta área.

\section{La información viaria del Ravennate relacionada con la vía XXIII}

Como complemento a la vía XXIII, se dispone de una fuente más que permita comprender el extremo occidental bético. Es uno de los trazados recogidos por el Ravennate (317, 17-15, versión de Parthey y Pinder, 1860) y no por el Itinerario de Antonino. Su disposición es la siguiente:

- 15 Onoba

- 16 Urion

- 17 Aruci

- 18 Fines

- 19 Seria 
Esta vía, si se acepta que la XXIII es marítima, es el único eje conocido a través de las fuentes itinerarias que conectaba Onoba con las zonas de interior y desembocaba hacia el valle del Ana y la zona central de la Lusitania. Está plenamente aceptado, como es lógico, que la última mansio no corresponde a Seria Fama Iulia, sino a Serpa, ya que las tres últimas mansiones de este tramo coinciden con las citadas en la vía XXII del Itinerario de Antonino.

De las otras mansiones citadas, la única conocida por Plinio es Onoba Aestuaria, reducida unánimemente en Huelva, a pesar de no haber pruebas epigráficas que lo demuestren. No obstante, es uno de los pocos casos en los que su reducción se puede considerar fiable a través de la posición citada en las fuentes.

Urion es, nuevamente, otro topónimo que tampoco puede ser demostrado por la epigrafía. Aparece también en Ptolomeo, quien la incluye dentro de las ciudades turdetanas; Correa (2016: 495) indica que la forma que da el Ravennate es tomada del griego, por lo que seguramente la fuente habría sido Ptolomeo. Se ha aceptado ampliamente la vinculación de su nombre con el yacimiento romano de La Dehesa (Luzón, 1975: 315-316; Vidal Teruel, 2001: 247), que sería el hábitat asociado para la explotación de Riotinto. El topónimo se vincula principalmente al no lejano río Urium (el actual río Odiel), lo cual tiene lógica dada la importancia económica y la necesidad de tener vía directa con Onoba. Además, es el único punto relevante hasta Arucci. De la provincia de Huelva es el lugar donde han aparecido más epígrafes. De uno de ellos, se intuye a través de una inscripción que fue una procuratela minera con administradores propios asignados (CIL II, 956). La única mención de origo corresponde a una inmigrante que cita el suyo como Novaugustana $(A E p .1965,300=C I L A$ 1, 39), lo que implica el traslado de gentes de otras áreas para trabajar de algún modo en la minería.

Las mansiones Arucci (Aroche) y Serpa (Serpa, Portugal), que no Seria (EspañaChamorro, 2018b), están reducidas por pruebas epigráficas, mientras que (Ad) Fines parece situarse por las millas, además de otros argumentos, en las proximidades de Vila Verde de Ficalho y Rosal de la Frontera; ya lo indicó el gran conocedor de la epigrafía hispana Hübner (1909: 2323); en esa entrada da 24 topónimos con Fines a lo largo de todo el Imperio. Del mismo modo Müller propone su ubicación en Vila Verde de Ficalho; Saavedra (1914) la ubica cerca de Paimogo por haber encontrado unas ruinas; Albertini (1923, 40), García Iglesias (1972, 165-178), Thouvenot (1973, 165 y mapa), Tovar (1974, 171), Roldán (1975, 237-238), Sillières (1990, 85), Corzo Sánchez y Toscano San Gil (1992) la proponen cerca de Rosal de la Frontera; Ramírez Sádaba (1994, 345-354), Lopes (1996, 68). Vid. la discusión al respecto, las pruebas sobre la ubicación de estas mansiones y la encastración del sistema viario trasfronterizo en este punto en España-Chamorro (2018b y 2019).

En definitiva, esta vía sí que muestra claramente una conexión entre la costa (Onoba) y el interior de la Baeturia celtica en conexión con el límite de la Lusitania y la vía XXI (Item de Esuri Pace Iulia) (vid. España-Chamorro, 2019a e/p); a diferencia del trazado interior que se ha querido ver para la vía XXIII, tiene una razón de peso: la conexión con el interior lusitano y la vía de exportación de las producciones mineras de Riotinto por el puerto marítimo de Onoba. 


\section{Conclusiones}

La complejidad de esta vía es patente. Los distintos autores que han tratado este trazado viario han dado razones de peso para considerar una u otra hipótesis. Sin embargo, por todo lo mencionado, las pruebas arqueológicas que evidenciaban su trazado interior a raíz de las pruebas aportadas no deben ser consideradas como tales, lo que ha posibilitado abrir el debate una vez más.

Que el Itinerario de Antonino recoja el trazado de la ruta marítima (vía XXIII), en vez de la ruta interior mencionada por el Ravennate, demuestra nuevamente que una de las fuentes que se usó fue un mapa (sobre la fuente primaria del Itinerario de Antonino ha habido un gran debate de si fue un mapa, otros itineraria scripta ed adnotata o una combinación múltiple). Me decanto por el uso de un mapa con adenda extraídas de itinerarios y mapas posteriores. Con respecto al debate, vid. Roldán (1975: 23 y ss.). Aspectos más recientes sobre el debate de si el Itinerario de Antonio se basó en un mapa pueden verse en Talbert (2008: 9-28). Se podría ver cómo, en este punto, la intención descriptiva está condicionada por la aprehensión de ese mapa, que en este punto sigue la forma peninsular y permite componer su imagen mental.

La comprensión de esta vía en su contexto sociohistórico y en la percepción hodológica que se tenía en la Antigüedad la dota de sentido; lejos de ser un camino marginal por zonas casi despobladas del extremo occidental de la Baetica, permite devolverle su importancia para la comprensión geográfica de la provincia y ver su imbricación con el resto del sistema viario bético-lusitano.

\section{Agradecimientos}

Este trabajo es fruto de mi investigación doctoral (Universidad Complutense de Madrid) y su publicación fue posible gracias a un contrato posdoctoral en la Escuela Española de Historia y Arqueología en Roma (EEHAR-CSIC). Agradezco a la Dra. Noemí Raposo Gutiérrez las valiosas informaciones sobre la minería onubense y sus sugerencias bibliográficas. 


\section{Bibliografía}

ALBERTINI, E., 1923, Les divisions administratives de l'Espagne romaine, París.

ALMAGRO GORBEA, M. y TORRES ORTIZ, M., 2009, La colonización de la costa atlántica de Portugal: ¿fenicios o tartesios?, Paleohispanica 9, 113-142.

ALVES DIAS, M. y RAMÍREZ SÁDABA, J. L., 2016, En torno al límite entre Lusitania y Bética. Estado de la cuestión, en J. CARBONELL MANILS y H. GIMENO PASCUAL (eds.), A Baete ad fluvium Anam: Cultura epigráfica en la Bética Occidental y territorios fronterizos. Homenaje al profesor José Luis Moralejo Álvarez, Alcalá de Henares, 23-40.

BENDALA GALÁN, M., 1986-87, Ab ostio fluminis Anae, CUPAUAM 13-14, 129-139.

BLANCO FREIJEIRO, A., 1962, Antigüedades de Riotinto, Zephyrus 13, 31-45.

CANTO DE GREGORIO, A., 1979, El acueducto romano de Itálica, $M M$ 20, 333

CARRASCO MARTIÁÑEZ, I., 2015, El ferrocarril minero del Guadiana. Historia de un tren olvidado, Huelva.

CEÁN J.A., 1832, Sumario de las antigüedades romanas que hay en España, Madrid.

CORREA RODRÍGUEZ, J.A., 2016, Toponimia Antigua de Andalucía, Sevilla.

CORZO SÁNCHEZ, R. y TOSCANO SAN GIL, M., 1992, Las vías romanas de Andalucía, Sevilla.

CORTIJO CEREZO, M. L., 2008, El itinerario de Antonino y la provincia "Baetica", Habis 39, 285-308.

DESSAU, H., 1914, 2. Rubrae (s.v.), en RE 2R 1Bd. I A. 1, 1166.

ESPAÑA-CHAMORRO, S., 2017, Los capita viarum de la Baetica, Anales de Arqueología Cordobesa 28, $11-32$.

ESPAÑA-CHAMORRO, S., 2018a, Miliarios y límites provinciales: Algunas reflexiones sobre el miliario de Mengíbar, CIL XVII/ 193 y la frontera oriental entre la Bética y la Citerior, Epigraphica $80,211-228$

ESPAÑA-CHAMORRO, S., 2018b, La frontera occidental de la Baetica con la Lusitania: (Ad) Fines, Serpa, Moura y la invención historiográfica de Arucci Nova, Rivista Storica dell'Antichità 48, 229- 255.

ESPAÑA-CHAMORRO, S., 2019a (en prensa), Item de Esuri Pace Iulia. Los problemas de la vía XXI del Itinerario de Antonino y el límite entre la Baetica y la Lusitania, Dialogues d'Histoire Ancienne 41-1.

ESPAÑA-CHAMORRO, S., 2019b, (en prensa) Corpus Milliariorum Baeticae. Miliarios y política viaria en la Hispania Ulterior Baetica en época imperial (s. I-IV), Archeologia Classica 69.

FABIÃO, C., 2002, Os chamados castella do sudoeste, arquitectura, cronologia e funções, AEspA 75, 177-193.

GARCÍA IGLESIAS, L., 1972, El Guadiana y los límites comunes de Bética y Lusitania, Hispania Antiqua 2, 165-178.

GONZÁLEZ FERNÁNDEZ, J., 1994, Cohors V Baetica, Habis 25, 179-188.

GONZÁLEZ FERNÁNDEZ, J. y PÉREZ MACÍAS, J.A., 1986, La romanización, Huelva en su Historia 2, 259-268.

GONZÁLEZ PONCE, F. J., 1990, Estrabón, Geografía III.5.2. [C167] y la concepción hodológica del espacio geográfico, Habis 21, 79-92.

JANNI, P., 1984, La mappa e il periplo. Cartografia antica e spazio odologico, Roma.

KOLB, A y ZINGG, L., 2016, The importance of internal borders in the Roman Empire: Written sources and model cases, en P. DELLA CASA y E. DESCHLER-ERB (eds.), Romes Internal Frontiers. Proceedings of the 2016 RAC session in Rome. Zurich Studies in Archaeology 11, 11-16.

LOPES, M.C., 1996, O territorio de Pax Iulia. Limites e Caracterização, Arquivio de Beja 2-3, serie III, 63-74. 
LÓPEZ SERRANO, L., 1999, Estudio de la macrofauna bentónica de la desembocadura del Río Piedras Huelva, Universidad Complutense de Madrid (tesis doctoral inédita).

LUZÓN NOGUÉ, J.M., 1975, Antigüedades romanas de la provincia de Huelva, en $M$. ALMAGRO BASCH y M. DEL AMO DE LA HERA (eds.), Huelva: Prehistoria y Antigüedad, 271-320.

MAIA, M., 1986, Os castella do Sul de Portugal, MM 27, 195-223.

MARCOS, S., 2011, Espace géographifique, espace politique: la frontière provinciale lusitanienne, une limite déterminante?, en A. CABALLOS RUBINO y S. LEFEBVRE (eds.), Roma generadora de identidades. La experiencia Hispana, Sevilla, 171184.

MELCHOR GIL, E., 2013, Entre la "urbs" y el "fundus": conmemoración funeraria y honorífica de las élites locales hispano-romanas en sus propiedades rústicas, Veleia 30, 119-142.

MORALES RODRÍGUEZ, E.M., 2001, Consideraciones sobre la municipalización flavia en la provincia de Huelva, Florentia Iliberritana 12, 307-314.

OZCÁRIZ GIL, P., 2006, Los conventus de la Hispania Citerior, Madrid.

PARTHEY, G. y PINDER, M. (eds.), 1848, Itinerarium Antonini Augusti et Hierosolymitanum: ex libris manu scriptis, Berlín.

PARTHEY, G. y PINDER, M. (eds.), 1860 , Ravennatis anonymi cosmographia et Guidonis geographica: ex libris manu scriptis, Berlín

PÉREZ MACÍAS, J.A., 2011, El Castillito Paymogo, Huelva, un castellum romano en las minas de la Rivera de Malagón, Actas de las I Jornadas de Patrimonio del Andévalo, Huelva, 127-150.

PÉREZ MACÍAS, J.A., 2015, Augusto y los distritos mineros del suroeste ibérico, en $\mathrm{C}$. MÁRQUEZ y E. MELCHOR GIL (coords.), La Bética en tiempos de Augusto. Aspectos Históricos y Arqueológicos, Córdoba, 285-371.

PHIL, E., 1921, Saxa Rubra, en RE 50 2R 3Bd. II A. 1, 807.
RAMÍREZ SÁDABA, J.L., 1994, La Baeturia céltica y los límites con Lusitania, Actas del II Congreso de Historia de Andalucía, Córdoba, 1991. Historia Antigua, Córdoba, 345-354.

ROBLES ESPARCIA, S., BERMEJO MELÉNDEZ, J. y CAMPOS CARRASCO, J., 2011-2012, La ciudad hispanorromana de Ostur, AAC 12-14, 75-94.

RODRÍGUEZ COLMENERO, A., FERRER SIERRA, S. y ÁLVAREZ ASOREY, R.D., 2004, Miliarios e outras inscricións viarias romanas do Noroeste Hispánico Conventos Bracarense, Lucense e Asturicense, Lugo.

ROLDÁN HERVÁS, J.M., 1975, Itineraria Hispana: fuentes antiguas para el estudio de las vías romanas en la Península Ibérica, = Anejo de Hispania Antiqua, Granada y Valladolid.

RUIZ ACEVEDO, J.M., 1998, Las vías romanas en la provincia de Huelva, Huelva.

SAAVEDRA, E., 1914, Discursos leídos ante la Real Academia de la Historia en la recepción pública de D. Eduardo Saavedra el 12 de diciembre de 1862, Madrid

SCHMIDT, M.G., 2013, Roads and towns along the border of Hispania Citerior, Tarraco Biennal: Congrés Internacional d'Arqueologia i Món Antic, Tarragona, 291-299.

SILLIÈRES, P., 1990, Les voies de communication de l'Hispanie méridionale, París.

TALBERT, R.J.A., 2008, Greek and Roman Mapping: Twenty-First Century Perspectives, en R.J.A. TALBERT y R.W. UNGER (eds.), Cartography in Antiquity and the Middle Ages. Fresh Perspectives, New Methods, Leiden-Boston, 9-29.

THOUVENOT, R., 1974, Essai sur la province romaine de Bétique, París.

TOVAR, A., 1974, Iberische Landeskunde, vol. II, Die Völker und die Städte des antiken Hispanien, tomo 1, BAETICA, = IL 2.I, Berlín

VIDAL TERUEL, N., 2001, La implantación romana en el extremo occidental de la Baetica: Doctrina y praxis en la ocupación del territorio onubense, Universidad de Huelva (tesis doctoral inédita).

VILLAR LIÉBANA, F., 2000, Indoeuropeos y no indoeuropeos en la Hispania prerromana, Salamanca. 
